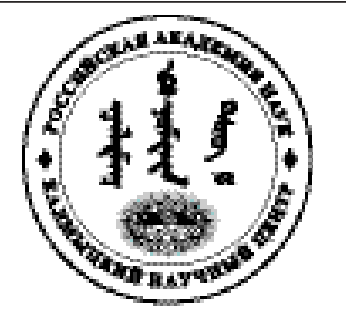

Published in the Russian Federation

Oriental Studies (Previous Name: Bulletin of the Kalmyk Institute

for Humanities of the Russian Academy of Sciences)

Has been issued as a journal since 2008

ISSN: 2619-0990; E-ISSN: 2619-1008

Vol. 13, Is. 5, pp. 1476-1487, 2020

DOI: $10.22162 / 2619-0990-2020-51-5-1476-1487$

Journal homepage: https://kigiran.elpub.ru

УДК 398.8

DOI: $10.22162 / 2619-0990-2020-51-5-1476-1487$

\title{
Словесно-поэтический репертуар башкирской свадьбы: прошлое и настоящее
}

\author{
Айгуль Мужавировна Хакимьянова
}

${ }^{1}$ Институт истории, языка и литературы Уфимского федерального исследовательского центра РАН (д. 71, пр. Октября, 450054 Уфа, Российская Федерация) кандидат филологических наук, старший научный сотрудник iD 0000-0002-2786-3477. E-mail: aihakim@bk.ru

(C) КалмНЦ РАН, 2020

(C) Хакимьянова А. М., 2020

Аннотация. Введение. Многосоставное представление башкирской свадьбы сопровождается гармоничным сочетанием нескольких видов искусства (музыка, поэзия, хореография, театр). В ней большая роль отводится словесным и песенным состязаниям (әйтеш), причитаниям (сенллу), благопожеланиям (теләк, алвыщ), песнопениям «яр-яр», величальным и прощальным песням, такмакам, которые органично вплетаются в ход свадьбы, создавая праздничную атмосферу, придавая особую важность всему происходящему. Свадебное слово, песнопение, речитации есть непосредственно функционально связанные с ритуальными действами содержательные компоненты, и они отражают древние мифологические представления, веру в силу слова и действий. Целью данной работы является анализ башкирского свадебнообрядового фольклора в единстве старинных традиций и современных нововведений. Результаты. Автор статьи рассматривает роль поэтических произведений в различных частях свадебного обряда. В статье прослеживается отражение эмоционального состояния невесты в различных поэтических текстах, обусловленное важностью момента перехода девушки в качественно иное состояние замужества; отмечается значимость особой смысловой нагрузки песен башкирской свадьбы для будущей семейной жизни.

Ключевые слова: фольклор, народное творчество, башкиры, свадебный обряд, музыкальная фольклористика, жанр, репертуар, слово, современность

Благодарность. Исследование проведено в рамках государственной субсидии проект «Духовная культура тюркских народов Южного Урала» (номер госрегистрации: AAAA-A17-117040350082-3).

Для цитирования: Хакимьянова А. М. Словесно-поэтический репертуар башкирской свадьбы: прошлое и настоящее // Oriental Studies. 2020. Т. 13. № 5. C. 1476-1487. DOI: 10.22162/26190990-2020-51-5-1476-1487 
UDC 398.8

DOI: $10.22162 / 2619-0990-2020-51-5-1476-1487$

\title{
Verbal and Poetic Repertoire of the Bashkir Wedding: Past and Present
}

\author{
Aigul M. Khakimyanova ${ }^{1}$ \\ ${ }^{1}$ Institute of History, Language and Literature, Ufa Federal Research Centre of the RAS (71, Oktyabrya \\ Ave., Ufa 450054, Russian Federation) \\ Cand. Sc. (Philology), Senior Research Associate
}

iD 0000-0002-2786-3477. E-mail: aihakim@bk.ru

(C) KalmSC RAS, 2020

(C) Khakimyanova A. M., 2020

\begin{abstract}
Introduction. Bashkir wedding is one of the most striking forms of traditional culture. Over centuries of evolution, a complex set of ideological and functional related ritual songs, actions, myths and rituals has formed as an integral festive and theatrical performance. This surprisingly unique performance (drama) reflects the worldview of the people, their poetic and musical culture, including peculiarities of social, everyday and social development. The ideology of caring for the welfare of the family and happy family future has been developed and vividly captured in the wedding rituals. Genotypic plans for the continuation of life, creating a sustainable family in order to ensure continuity and fertility of the new family member — sister-in-law — is a major determining code of the Bashkir wedding manifested in the complicated mytho-ritual complex tui (wedding, feast). In it, a large role is given to verbal and song contests (Bash. әйтеш), lamentations (сецләу), good wishes (теләк, алвыли), 'yar-yar' chants, magnificence and farewell songs (takmaks) which are organically woven into the course of the wedding to create a festive atmosphere, give special importance to everything that happens. These work of art have various and rather complex functions, since they not only accompany various moments of the wedding celebration, but also reflect ancient mythological ideas, belief in the power of words and actions. The verbal, song and action creative complex acts as a single syncretic whole with what is happening. Goals. The article examines the role of verbal and poetic works in various parts of the wedding ceremony. They are distinguished by a variety of texts and tunes dedicated to various moments of the wedding and ritual actions addressed to the bride and groom (mostly). Results. The ritual of good wishes goes back to the magic of a kind word, which in general in all types of rituals involves the structuring of events in the name of blessings and the consolidation of a happy future. The article traces the reflection of the emotional state of the bride in various poetic texts, which determines the importance of the moment of the girl's transition to a qualitatively different state of marriage; the importance of the special semantic load of the songs of the Bashkir wedding for the future family life is noted. In all cultures, edification, parting words generalize the prescriptions and rules of behavior for young people. There are two main places of well-wishes in the wedding drama: in front of the wires from the father's house (girdling) and in the groom's house (opening the face). Good wishes and edifications, pronounced in the rites of transitional meaning, represent a kind of collection of etiquette, everyday life and traditions of the people. This is the poeticized wisdom and life experience of people who want the well-being of a girl who goes into a 'foreign' environment. In a Bashkir wedding, songs of a greatness, entertaining or humorous nature are performed, which are organically included in the drama of the wedding action and become an integral part of the ceremony as a whole.
\end{abstract}

Keywords: folklore, folk art, Bashkirs, wedding ceremony, musical folklore, genre, repertoire, word, modernity

Acknowledgements. The reported study was funded by government subsidy — project name 'Turkic Peoples of the Southern Urals: Spiritual Culture' (state reg. no. AAAA-A17-117040350082-3).

For citation: Khakimyanova A. M. Verbal and Poetic Repertoire of the Bashkir Wedding: Past and Present. Oriental Studies. 2020. Vol. 13(5): 1476-1487. (In Russ.). DOI: 10.22162/2619-0990-202051-5-1476-1487 


\section{Введение}

Традиционная башкирская свадьба представляет собой организованное театрализованное действо. В традиционной свадьбе тесно переплетаются магические обряды, заговоры и приговоры, песни и танцы, игры и плачи. Трехступенчатость и многосоставность брачного туй 'свадьба, пир' вполне вписывается в типологически универсальный сценарий тюрко-монгольской свадебной культуры (башкир, казахов, киргизов, алтайцев, монгол, туркмен, татар, ногайцев, узбеков и др.).

Неотъемлемой частью башкирского свадебного обряда является исполнение песен (йыр), такмаков ${ }^{1}$ (такмак), благопожеланий (теләк, алвыщ), напевных речитаций (көйлө hамак), мелодий (көй), а также приговоров (әйтем), многочисленных малых форм словесных маркеров (реплики, загадки, приметы, запреты и т. д.), имеющих разнообразные и достаточно сложные функции, так как они не только сопровождают различные моменты свадебного «представления», но и создают целостность многосоставного и многофункционального обряда.

Цель статьи - выявить и рассмотреть словесно-поэтические тексты в комплексе с функционально связанными с ними обрядами. Основная суть состоит в том, чтобы показать процессы трансформации, изменений и бытования свадебно-обрядового поэтического репертуара во времени. Словесно-поэтический репертуар (свадебные песни, сеңләу 'причитания', такмаки 'частушки', напевные теләк 'благопожелания', мактау 'восхваления' и т. д.) представлен в разновременной фиксации и сохранности, т. е. с XIX в. по сегодняшний день, что представляет особо важную, актуальную проблему изучения вторичного и третичного фольклора.

В качестве материала исследования выступил словесно-поэтический репертуар башкирской свадьбы в разновременных

1 Такмак - жанр музыкально-поэтического фольклора у башкир и ряда других народов. Такмаками называют разновидность скорой песни, припевок к пляскам. Такмаки бывают разнообразные по характеру, в том числе свадебные. записях. Для его изучения в статье применялись сравнительно-сопоставительный, текстологический, аналитический методы исследования.

\section{Причитания}

Главным жанром башкирского туй ‘свадьба, пир' являются сеңллу ‘причитания'. Причитание девушки перед отправлением в дом мужа называется у башкир сеңллу, у татар - кыз елату (досл. 'заставить плакать девушку') [Исхакова-Вамба 1997: 52], у казахов - cblнcbly и т. д. и генетически связан с магией плача, с идеей перехода молодой в «чужой» мир рода жениха. Переходные моменты, «смерть, роды и вступление в брак сопровождались особым ритуалом прощания» [Еремина 1987: 28], санкционирующим по сути обновление статуса. По утверждению К. Мэргэна, первоначальной функцией сенляу было «прощание с „хозяевами“ оставляемой родины, получение благословения со стороны порожденных древним сознанием домовых, владыки земли и вод, а в некоторых случаях - обращение к родовому тотему с просьбой не забывать ее и не оставлять без своего покровительства» [Мэргэн 1976: 53]. Р. А. Султангареева выделяет несколько ритуальных функций сенляу: «плачевное самовыражение невесты как прощальное очищение перед обновлением; брачное испытание невесты и способ передачи „своейе и ,чужойе сторон; умилостивление божеств, символичное оплакивание временной „социальной смерти“ для своего и „оживленияе для чужого рода» [Султангареева 2006: 157]. Л. К. Сальманова прощальный обряд сенляу связывает с поэтапным уходом невесты из родительского дома в чужой мир, изменением социального статуса невесты: «В этом церемониале прощания, по-видимому, отражается элемент эпохи материнско-правовых отношений, так как он начинается с получения невестой благословления у матери. Затем она переходит к отцу и младшим братьям и сестрам. С последними она прощается во дворе... Завершая обход, она возвращается в родительский дом, являющийся центром ее упорядоченного мира. Отсюда начинается ее поэтапный уход в чужой мир, что фиксируется повязыванием пучков нитей на матицу дома» [Сальманова 2007: 128-129]: 
Аршынн да аршылн ак ука алдымм

Акбуз̧ аткайьма дилбегә.

Илап та илап сук бәйләйем

Тыуган илкәйемә билгегә.

$Э \check{u}-\breve{u}-\breve{u}$

[НА УФИЦ РАН. Ф. 3. ОП. 2. Д. 453. Л. 325]

По специфике поэтико-образного, эмоционально-экспрессивного, функционального строя сенляу условно подразделяют на сенляу-раздумья, сенляу-обращения и сенляу-обругивания [БНТ 2010: 60]. Сенляу-раздумья исполнялись во время про-

Етеган тигән ете йондоз,

Өлкәрзәрен ташлап китә алмай.

Кыз балакай ниңз илай тиһәң,

Йорт-илкәйен ташлап китә алмай.

$Э \check{u}-\check{u}-\check{u} .$.

[ПМА 2010:1]

Наиболее распространенными являются «укорительные» сенляу-обращения новобрачной к близким родственникам отцу, матери, брату, его жене. Прощание с самым близким и дорогим, связанным с мо-

Бура ла бура ашыңуды

Ашатманың да, атакай.

Төймәләй генә башымды

Йәшәтмәнең дә, атакай.

$Э \check{u}-\breve{u}-\breve{u} \ldots$

Капкаларзан сыккан сакта

Пар аттары тулай башланы.

Һау бул да, әсәкәйем, тигән инем,

Барыһы ла илай башланы.

$Э \check{u}-\check{u}-\breve{u} .$.

[Хакимьянова, Султангареева 2018: 89-99]

Исполняемые также в последний день свадьбы сенляу-обругивания или корильные величания превращаются в развернутую сцену хуления (хурлау) жениха и его род-

Кейәу зу кейәу тинегез ,

Кейоүгендгез шулмы ни?

Аявы салвы һабындай,

Ауыззы казан кабындай.

[Хакимьянова, Султангареева 2018: 105-106]
Аршинами да ариинами бельій позумент

Украсит вожжи сизого коня.

Плача-рыдая повязываю нить -

Родной земле моей на пометку.

$Э \check{u}-\check{u}$-й.

щания с полем, когда девушка вешала свой девичий головной убор - такию на дерево, вокруг которого ее подружки водили хороводы. Они посвящены судьбе нареченной, родной стороне, людям, которых оставляет невеста:

Большая Медведииа - семь звёзд,

Плеяду свою не может оставить.

Дева юная потому и плачет,

Что родину свою неможет оставить.

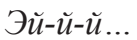

лодостью, превращается в драматическое зрелище. В этих сенляу-обращениях одновременно отражены чувства боли и любви, разлуки, а также упреки:

Хлева твои полны хлебов,

Да не дал мне ты, отеи.

Головушке, что с пуговку,

Не дал пожить здесь, отеи.

Эй-й-й...

Когда я выходила за ворота

Вруг кони стали брыкаться-играть.

Когда сказала, „прощуай, мамочка",

Все стали плакать и стенать.

Эй-й-й...

ственников. Высмеивание всех «чужих» основывалось на поверьях, по которым сквернословие предохраняет от дурного глаза: 
Яркой и проникновенной силы образное поэтико-художественное воплощение полу- чают откровения, построенные на осознании невозможности возвращения:
Һез тиңдәштәремдән айьрылһам, Кауырһынкай булып кайтырмын! [БHT 1995: 463]

Переход в новый статус ассоциируется со встречей с незнакомым, чуждым и чу-

Иламас та ине, ай, кыз бала,

Сит ерззргә бара, югала.

[БHТ 1995: 454]

Так, по представлениям, переход этот возможен был только через прекращение добрачного существования, т. е. через умирание [Бернштам 1982: 63]. Именно в таком контексте объяснимы универсалии оплакивания девичества и плачевного расставания.

\section{Свадебные песни}

Свадебные песни жизнеутверждающего характера образуют особую группу, в

\section{Котло күңелең менән кил, \\ Киленебез, йәр-йәр! \\ Төкле аявың менән кил, \\ Киленебез, йәр-йәр!}

[БНТ 1995: 481]

Исполнение «яр-яр» поныне сохраняется во многих свадьбах тюркских народов (таджикских, узбекских, казахских, туркменских и т. д.), их отличает жизнерадостный поздравительный тон, но они различаются в функциональном плане. Например, в казахской свадьбе «жар-жар» - это поэтический разговор, состязание между девушкой и егетом [Аргынбаев 1974: 68-77; Каскабасов 1985: 115-137], в туркменской свадьбе - прощальные песни во время про-

\section{Алыс̧ ерз̧ән килдек без̧, \\ Кызыл итек кейзек без̧. \\ Атаһынан-индһенән \\ Айырырва килдек без. \\ [Султангареева 2006: 166]}

Этот обычай сохранил древние отголоски магии вечного разрыва и неприкосновенности лиц, переходящих в разные статусы.
Когда с вами расстанусь, подруженьки, Перышком только вернуться смогу!

жим, что, согласно логике, по самым этим показателям уже опасно:

Не плакала бы дева,

В чужсие страны уходит, исчезает.

которую входят песнопения «яр-яр» (йәрйә $p^{2}$ или же йәр-йәр әйтеу), напевные благопожелания (теләк, алвыш, батаһүз) и свадебные величальные песни. Песнопения йәр-йәр занимают особое место в башкирской свадьбе. По сведению информантов, исполнение песнопений йәр-йәр приходится в основном к моменту ухода невесты из дома и встречи ее в доме свекрови:

Принеси ты счастье в дом,

Невестушка, яр-яр!

С легкой ножки заходи,

Невестушка, яр-яр!

водов невесты в дом жениха [Абубакирова 1982: 14]. В башкирской свадьбе, как и у туркмен, исполнялись благопожелания йәрйәр и причитания йәр-йәр. Примечательна переходная символика песнопений «яр-яр», запечатленная в башкирском свадебном обряде кыз озатыу ('проводы девушки'). Невесту и мать разлучали таким образом: женщины обхватывали их полотенцами и тянули в разные стороны, плача и причитывая йәр-йәр:

Издалека приехали мы, Красные сапожки одели мы. От отия и матери

Отлучить приехали мы.

Некоторые образцы йәр-йәр представляют песни-восхваления, которые идеализируют невесту, жениха или же всю свадьбу:

${ }^{2}$ Йәр в переводе с башкирского означает ‘любимый/-ая’, ‘возлюбленный/-ая’. 
Һыльуузарзың араһьнда

Бер һылььуһьың, йар-йар.

Әхирәттор араһында

Бер йондозһон, йәр-йәр!

[БНТ 1995: 481]

Ныне песнопения «яр-яр» исполняются ради традиции (Альшеевский, Янаульский, Давлекановский р-ны Республики Башкортостан). Они поются на особом скором темпоритме, отличительном жизненном пафосе, нежели причитания.

\section{Благопожелания}

Каждый этап башкирской свадьбы сопровождается определенными обрядами с благопожеланиями (алвыли, теләк), поскольку слову придавали огромное зна-

Бил, бил биләйем,

Коткайынды биләйем.

Байльвыңды бирәйем,

Берга кушып байләйем.

Бил тиңенте биләйем,

Ак һүземде теззйем,

Пак һүземде тезәйем.

Кырын һүз кырга китиен,

Кара күз һулва китиен.

Бил, бил биләйем,

Коткайьцңды бәйләйем!

[БНТ 1995: 472]

Благопожелания и назидания - это опоэтизированная мудрость и жизненный опыт людей, желающих благополучия девушке, уходящей в «чужую» среду. Произнесением напутствий обозначалась грань между прошлым и будущим невесты [Хакимьяно-

Түлле, түлле, түлле бул,

Бүзана кеуек түлле бул,

Тулгатканын ул бульын,

Тумырганың май булһын.

Иренмәһән - игез тап,

Арыммаһан - ай з̧а тап,

Йыбанмаһан - йыл да тап!

[БНТ 1995: 484]

Благопожелания (теләк, алвыи) должны были произносить невестке все женщины - родственницы жениха. Согласно идее материализации доброго слова, алвьи «закрепляли» преподнесением даров: невестке
Среди всех красавии

Tыл самая красивая, яр-яр.

Среди подруг ты самая

Яркая звезда, яр-яр!

чение. Они, как правило, исполняются говорком на несложный речитативный напев и отличаются многообразием текстов и напевов, приуроченных к различным моментам свадьбы. Выделяются основные два места исполнения благопожеланий невесте: перед проводами из дома отца (бил быуызу 'опоясывание') и в доме жениха (бum acbly 'открывание лица'). Например, во время опоясывания невесты (бил быуыly) сноха обвязывает и произносит:

Талию, талию обвязываю,

Удачу я привязываю.

Богатство и счастье

Вместе привязываю.

Талию твою обвяжу

Светлые пожелания скажу,

Благое слово я скажу.

Плохие слова и недобрые взгляды

Пусть всегда тебя обойдут стороной!

Талию, талию обвязываю,

Удачу я привязываю!

ва, Султангареева 2018: 113]. В них отражаются как духовно-нравственные жизненные принципы, так и бытовые предписания и напутствия. Основное пожелание касается всегда плодовитости невестки:

Плодовитой будь, будь,

Словно перепелка будь,

Схватки будут - сына рожай,

То, что берешь - масло будет пусть!

Коль не лень - двойню рожай,

А не устанешь - каждый месяи рожай,

Коль по силам - каждый год рожай!

на плечи укладывали платочки, полотенца, платки, пришивали на елән ${ }^{3}$ ('Зилян') мо-

${ }^{3}$ Башкирская национальная верхняя длиннополая одежда с длинными рукавами и обязательно на подкладе. 
нетки, на пальцы надевали кольца, на руки браслеты и т. д. Устойчивость и привлечение добрых наставлений обыгрывается та- ким образом: каждое слово сопровождалось ритмичным похлопыванием по плечам новобрачной.

On - on - on!

Будь белее яйща,

$\mathrm{On}-\mathrm{On}-\mathrm{On!}$

Будь осторожнее сороки, Будь чище воды текучей!

всеобщее оживление. Свекровь подносит новобрачным мед и масло и приговаривает:

Пусть речи будут сладкими, какмед,

Душа, как масло, будет мягкой!

Пусть дороги будут светльми,

Жизнь ваша будет в достатке!

торый она должна наступить, и приговаривают: Төшкән еренуә таш бульлn бат! ('На этом месте пусть камнем останется!') или hаува баткан таштай бул! ('Как в воду канувшим камнем будь!') [ПМА 2011: 3]. Символика камня действует в значении обеспечения крепости и устойчивости.

Невозможно представить башкирскую свадьбу без песен, сопровождающих все этапы церемонии, органично включающихся в драматургию действия и становящихся неотъемлемой частью обряда в целом. В основном это были песни величального, развлекательного или шуточного характера. В величальных песнях, открывающих свадьбу и посвященных родственникам жениха, восхваляются слава и могущество сватов, доблесть их батыров и красота женщин:

Сват ты наш, ой, да mbl,

Чернее бровей глаза твои.

Словно трели соловья

Певучи твои слова.

тов йырлап кәсә биреу (досл.: 'подача чаши с песней'), в чашу с обрядовым напитком опускают монету:

\footnotetext{
3 Завязка, подвязка - мифологизированный предмет. Входит в число подарков невесты, кото-
}

рые она раздает мальчишкам рода. Символ силы, охраняет от сглаза. 


\section{haü!}

Йүгәнһез зу аттың йүне юк,

Көрәгәһез корзон, кото юк.

Көмөш кена тәңєк һальп бирзем, коза, Эсмәй генә куйһан, кәзер юк!

[БНТ 1995: 435]

Тот, кому посвящается песня, допивает и берет себе монету, дав знать тем самым свое

\author{
Юл буйьнда юрвалаван \\ Бүзәнәнен, балаһы. \\ Йырлап бирәм коз̧асава - \\ Илебез̧зие йолаһы.
}

[БНТ 1995: 446]

Традиционные в свадебных торжествах обрядовые песни помогают установлению доверительных, дружеских отношений брачующихся сторон, в них благословляют новобрач-

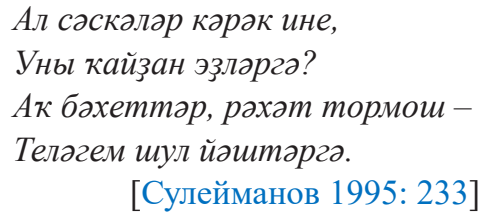

Котло булһын туйывыз, Изге булиын уйывъыз’! Шәп кунактар килгән без̧гә, Берга булһын туйыхыз̧!

[ПМА 2010: 2]

Застольные песни затрагивают любые темы из жизни и непосредственно касающиеся события, ради которого собрались гости. Музыкально-поэтическая структура этих песен четырехстрочная, реже двухстрочная, с обязательным характерным припевом, который, обычно, подхватывают все присутствующие [Хакимьянова 2014: 125]. Каждое слово песни несет в себе огромную смысловую нагрузку и силу психологического воздействия.

\section{Такмаки}

Такмак в современной башкирской свадьбе является одним из мобильных и еще
Xaü!

Без узды от коня и проку нет,

На столе без медка и смаку нет.

Кладу серебряную монету в чашу тебе,

Не выпьешь, сват, уваженья нет!

почтение. Чаще за чашу, преподнесенную с песней, полагалось ответить песней:

\author{
Это птенчик перепелки \\ Вдоль дороги семенит. \\ Поднесу с песней чашу свахе, \\ Как обычай наш велит.
}

ных, восхваляют сватов, благодарят хозяев за превосходное угощение и т.д. Во время свадебного застолья часто звучат песни-поздравления и песни-благословления молодым:

Цветы алье нужны,

Где же их искать нам?

Светлое счастье, ладную жизнь

Желаю я молодым!

Пусть удачной будет свадьба, Пусть добро лишь движет вами! Замечательные гости

Веселятся вместе с нами!

не потерявших актуальность жанров. Такмаки отличает искрометный юмор, огромный жизнеутверждающий пафос и эмоционально-экспрессивная выразительность [Хакимьянова 2019: 498]. Основная часть такмаков служит для шуток между гостями, а также для обличения нерадивого жениха или его приближенных. Обряд обругивания, охаивания сватов, гостей, жениха имеет место на всем протяжении башкирской свадьбы. Традиционный художественный прием в поэзии охаивания - описание внешнего облика и физических качеств конкретного свадебного персонажа (жениха, свата и т. д.) в нарочито уродливых формах:

На макушке такии курая

Воробушек желтый гнездится.

В бороде женишка этого

Мыцка ведь копошится. 
Аръякта ла комалак,

Биръякта ла комалак.

Һез̧зен яктың козалары -

Кап-кара ла тумалак.

[Баимов 2001: 180].

В башкирской свадьбе такмаки сопровождают эпизоды прихода свата - яусы килеу, йыуаса, танцы сватов - коза бейеүе, увеселения во время подворных хождений - haбa üblübly, испытания в виде танца жениха - кейәү бейеуе и проводы сватов

\section{Без̧зенц коза хәлле икән,}

Йыуасаһь балль икән.

Биманмаһан, ашап кара,

Шәкәр-балдан татлы икән!

[Экспедиционные материалы 2003: 248]

Эти такмаки исполняются во время свадебного угощения гостинцами, привезенными свахами с обеих сторон. Йыууаса собирательное название угощений, которые предназначены для совместного обрядового чаепития роднящихся сторон. Традиционны выносы йblyaca или чак-чак на подносе. По

\section{Токтон ауыз̧ын асайык, Йыуасаһын сәсәйек. \\ Козавыйзың күнеле булььн, \\ Бөтөргәнсе ашайык..}

[Хакимьянова, Султангареева 2018: 69]

Мгновенность сочинения, картинность такмаков дают представления о башкирском mуй как об одном из самых жизнесмысловых событий, в котором соединяются все противоречия и решаются вопросы бытия.

Свадебный танец - самый веселый и

Без̧зен коз̧а бейеп йөрөй,

Бейеуенен рәте юк.

Коза бульп килгән булван,

Бер бейерга хәле юк.

Лавкаларва бара hальın,

Cитса тауар алайым.

Козаларзың күңеле бульын,

Бер-ике басьыn алайьм.

[ПМА 2016: 5]
На одной сторонке хмель, Хмель и на другой сторонке.

Сваты с вашей стороны -

Все черны и толсты.

- хуш ите. Такмаки, посвященные обрядовому угощению йыуyaca, являются одним из самых распространенных и устойчивых обычаев по сей день в свадебном обряде башкир:

Говорят, наш сват богат,

С.медом у них йыуаса.

Не поверишь, так попробуй -

Сахара-меда слащче она!

обычаю, отведав угощение, гости бросают монеты на поднос. Поэтический репертуар этого обряда составляют такмаки, основное содержание которых сводится к комментированию действ, констатированию обряда, оценке поведения, эмоций и характеров гостей:
Развяжи скорее узел
Угости всех йыуасой.
Пусть порадуется сваха,
До конияа съедим мы все.

оживленный, полный разных эмоций, оценок, дающий возможность для выяснения взамоотношений, похвал, иронии обрядовый эпизод. Основная функция танцевальных такмаков - подбадривание, подзывание к танцу и веселью:

Сват пустился в круг плясать, Да у него не ладится.

Тоже мне - явился в гости,

Того гляди свалится.

В лавку сбегаю я мигом, Ситеи нужен мне как раз. Гостям нашим на утеху Пройдусь по кругу пару раз! 
Танец невестки отражает своеобразный этикет знакомства молодой с родней жениха. Во время общего веселья под плясовую музыку невеста танцует на подносе, гости бросают к ее ногам деньги, которые собирают жених и его друзья, затем передают молодым. Характерны приметы, сопровождающие свадебные танцы: «если невеста кружится сильно и дробит - детей будет много», «если жених дробит сильно - быть благополучию», «если свекровь не станцует на сундуке - отношения между сторонами будут натянуты или не будет покоя» [БНТ 2010: 65-66].

Башкирское свадебное творчество ныне переживает сложный процесс трансформаций и изменений. Обрядовое слово утеряло магизм, древнюю символику, образцы разных жанров исполняются "ради обычая». Поэтические тексты преимущественно имеют назидательную, поучительную направленность, исполняются в напевно-речитативной форме. Свадебные причитания в их функциональности уже не являются обязательным атрибутом современной обрядности, но устойчивы в памяти населения, о чем свидетельствуют современные записи. От благопожеланий, в прошлом широко развернутых по содержанию, ныне сохранились лишь фрагменты, звучащие в форме поучений. Во время хождений «К воде» ныне стало позволительно присутствовать и мужчинам, также петь всем, танцевать, устраивать выкупы воды. Надо признать, что ранее этот обряд был глубоко сакрален и участвовали в нем только женщины. Процессия хождения за водой представляет яркое увеселительное

\section{Источники}

НА УФИЦ РАН - Научный архив Уфимского федерального исследовательского центра PAH.

Экспедиционные материалы 2003 - Экспедиционные материалы - 2003: Зилаирский район / сост. Г. Р. Хусаинова, Р. А. Султангареева, Г. В. Юлдыбаева, Г. М. Ахметшина, Ф. Ф. Гайсина, Л. К. Сальманова, Т. И. Файзуллин. Уфа: ИИЯЛ УНЦ РАН, 2006. 252 с.

\section{Полевой материал автора}

ПМА 2010 - Полевые материалы, собранные автором в 2010 г. Фольклорный фонд ИИЯЛ УФИЦ РАН: зрелище с участием ряженых цыган, матросов, женщин, переодетых в мужчин, и наоборот. Если ранее во время встречи молодоженов их угощали медом и маслом, то в настоящее время под влиянием русской культуры и традиций устройства официальных церемоний в некоторых районах молодоженов начали встречать хлебом и солью. Многие обряды, утеряв первоначальные замыслы, приняли развлекательный, игровой характер - это прощальный пир, пляски йblyaca, прятания невесты, «женихова баня» и др. Излюбленным развлечением стали проводы сватов в баню с усаживанием их в корыто, состязания сватов «в краже» головных уборов и т. д. Меняются образы, персонажи, сюжеты, но стиль, эстетика отображения событий, направленность песен, такмаков остаются функциональными и традиционными.

\section{Заключение}

Словесно-поэтический репертуар башкирской свадьбы имеет прочную, отшлифованную веками основу. Башкирская свадьба богата песенным фольклором, который все еще сохраняется в памяти носителей традиций. Песни, такмаки, благопожелания, речитации сопровождают все важнейшие обрядовые действия, и каждый из них занимает определенное место в традиционной свадебной церемонии. Если в прошлом основными эмоциональными кодами, выраженными в жанрах традиционной свадебной обрядности, были плачевно-прощальные, напутствующие и подбадривающие, то эмоциональный пафос современной свадьбы - выраженно-веселый, направленный на зрелищность и развлечение гостей.

\section{Sources}

Ufa Federal Research Centre of the RAS, Scientific Archives.

Khusainova G. R. et al. (comps.) Expedition Materials - 2003: Zilairsky District (Bashkortostan, Russia). Ufa: Institute of History, Language and Literature (Ufa Scientific Centre of RAS), 2006. 252 p. (In Bash.)

1. Записано в 2010 г. от Рахметовой Зулейхи Хусаиновны (1941 г. р.), жительницы дер Турат-Ильясово Хайбуллинского района Республики Башкортостан. 
2. Записано в 2010 г. от Юнысовой Багизы Мухаметкиреевны (1925 г. р.), жительницы дер. Абиш Хайбуллинского района Республики Башкортостан.

ПМА 2011 - Полевые материалы, собранные автором в 2011 г. Фольклорный фонд ИИЯЛ УФИЦ РАН:

3. Записано в 2011 г. от Нигаматуллиной Танзили Мужавировны (1968 г. р.), жительницы г. Белорецк РБ.

ПМА 2014 - Полевые материалы, собранные автором в 2014 г. Фольклорный фонд ИИЯЛ УФИЦ РАН:

4. Записано в 2014 г. от Хужахметовой Закии Галиевны (1939 г. р.), жительницы дер. Ахмерово Ишимбайского района РБ.

\section{Author's Field Data}

Informant: Bagiza M. Yunysova, b. 1925. Rec. in Abish (Khaybullinsky District, Republic of Bashkortostan, Russia) in 2010. (In Bash.)

Informant: Maryam Z. Khusnekhuzhina, b. 1930. Rec. in Kalu-Ayry (Ishimbaysky District, Republic of Bashkortostan, Russia) in 2016. (In Bash.)

Informant: Minlebanu S. Tarkhanova, b. 1927. Rec. in Chebarkul (Salavatsky District, Republic of Bashkortostan, Russia) in 2018. (In Bash.)

Informant: Tanzilya M. Nigamatullina, b. 1968.

\section{Литература}

Абубакирова 1982 - Абубакирова Н. Н. Народные песни Западного Туркменистана: дис. ... канд. искусствовед. Л., 1982. 24 с.

Аргынбаев 1974 - Аргынбаев X. А. Свадьба и свадебные обряды у казахов в прошлом и настоящем // Советская этнография. 1974. № 6. С. $68-77$.

Баимов 2001 - Баимов Б. С. Башкирские народные такмаки. Уфа: Аэрокосмос и ноосфера, 2001. 224 c.

БНТ 1995 - Башкирское народное творчество. T. 1. Обрядовый фольклор / сост., авт. вступ. ст. и коммент. А. М. Сулейманов, Р. А. Султангареева; отв. ред. Г. Б. Хусаинов. Уфа: Китап, 1995. 560 с. (на башк. яз.)

БНТ 2010 - Башкирское народное творчество. Т. 12. Обрядовый фольклор / сост., авт. вступ. ст. и коммент. А. М. Сулейманов, Р. А. Султангареева; отв. ред. Н. Т. Зарипов, Р. М. Юсупов. Уфа: Китап, 2010. 592 с.

Бернштам 1982 - Бернштам T. А. Образ «расставания с красотой» (к семантике некоторых
ПМА 2016 - Полевые материалы, собранные автором в 2016 г. Фольклорный фонд ИИЯЛ УФИЦ РАН:

5. Записано в 2016 г. от Хуснехужиной Марьям Зиевны (1930 г. р.), жительницы дер. Калу-Айры Ишимбайского района РБ.

ПМА 2018 - Полевые материалы, собранные автором в 2018 г. Фольклорный фонд ИИЯЛ УФИЦ РАН:

6. Записано в 2018 г. от Тархановой Минлебану Сафиевны (1927 г. р.), жительницы дер. Чебаркуль Салаватского района РБ.

7. Записано в 2018 г. от Ахтаровой Земфиры Баруазовны (1949 г. р.), жительницы дер. Лагерево Салаватского района Республики Башкортостан.

Rec. in Beloretsk (Republic of Bashkortostan, Russia) in 2011. (In Bash.)

Informant: Zakia G. Khuzhakhmetova, b. 1939. Rec. in Akhmerovo (Ishimbaysky District, Republic of Bashkortostan, Russia) in 2014. (In Bash.)

Informant: Zemfira B. Akhtarova, b. 1949. Rec. in Lagerevo (Salavatsky District, Republic of Bashkortostan, Russia) in 2018. (In Bash.)

Informant: Zuleykha Kh. Rakhmetova, b. 1941. Rec. in Turat-Ilyasovo (Khaybullinsky District, Republic of Bashkortostan, Russia) in 2010. (In Bash.)

элементов материальной культуры в восточнославянском свадебном обряде) // Памятники культуры народов Европы и Европейской части СССР. Л.: Наука, 1982. С. 43-66.

Духовные сокровища 1992 - Духовные сокровища. Фольклор аслыкульских, демских, уршакских башкир / сост. Ф. А. Надршина. Уфа: РЦНТ, 1992. 76 с. (на башк. яз.)

Еремина 1987 - Еремина В. И. К вопросу об исторической общности представлений свадебной и погребальной обрядности (невеста в черном) // Этнографические истоки фольклорных явлений: Русский фольклор. Т. XXIV. Л.: Наука, 1987. С. 21-32.

Из памяти народной 2012 - Из памяти народной - народу (первые труды башкирских фольклористов) / сост., авт. вступ ст. и глоссария Р. А. Султангареева. Уфа: УГАИ, 2012. 134 с. (на башк. яз.).

Исхакова-Вамба 1997 - Исхакова-Вамба Р. А. Татарское народное музыкальное творчество. Казань: Татар. кн. изд-во, 1997. 264 с., с нотами. 
Каскабасов 1985 - Каскабасов С. А. Театральные элементы в казахских обрядах и играх // Фольклорные жанры народов СССР. М.: Наука, 1985. С. 115-137.

Мэргэн 1976 - Мэргэн К. А. Семейно-бытовые обряды // Литература. Фольклор. Литературное наследие. Уфа: изд-во БГУ, 1976. C. $31-76$.

Сальманова 2007 - Сальманова Л. К. Причитания и обряды перехода в традиционной свадьбе башкир // Ватандаш, 2007. № 1. С. $128-129$.

Сулейманов 1995 - Сулейманов Р. С. Жемчужины народного творчества Урала. Уфа: Китап, 1995. 248 с.

\section{References}

Abubakirova N. N. Folk Songs of Western Turkmenistan. Cand. Sc. (art studies) thesis abstract. Leningrad, 1982. 24 p. (In Russ.)

Argynbaev Kh. A. Kazakh wedding and its rites: past and present. Sovetskaya etnografiya. 1974. No. 6. Pp. 68-77. (In Russ.)

Baimov B. S. Bashkir Folk Takmaks. Ufa: Aerokosmos i Noosfera, 2001. 224 p. (In Russ.)

Bernshtam T. A. The image of 'bidding farewell to beauty': semantics of some material cultural elements in East Slavic wedding rites revisited. In: Cultural Monuments of Europe and European Soviet Republics. Leningrad: Nauka, 1982. Pp. 43-66. (In Russ.)

Eremina V. I. The bride-in-black: historical commonality of wedding and funeral rites revisited. In: Ethnographic Roots of Folklore Phenomena. Ser.: Russian Folklore. Leningrad: Nauka, 1987. Vol. XXIV. Pp. 21-32. (In Russ.)

Iskhakova-Wamba R. A. Tatar Folk Music. Kazan: Tatar Book Publ., 1997. 264 p. (In Russ.)

Kaskabasov S. A. Kazakh rites and games: theatrical elements. In: Folklore Genres of Soviet Peoples. Moscow: Nauka, 1985. Pp. 115-137. (In Russ.)

Khakimyanova A. M. Bashkir folk takmaks. Oriental Studies. 2019. No. 3. Pp. 492-501. (In Russ.) DOI: 10.22162/2619-0990-2019-43-3492-501

Khakimyanova A. M. Table songs of the Bashkirs. In: A. Kharisov and Topical Issues of Philology. Conference Proceedings. Ufa, 2014. Pp. 123-
Султангареева 2006 - Султангареева P. A. Жизнь человека в обряде. Уфа: Гилем, 2006. С. $120-142$.

Хакимьянова 2014 - Хакимьянова А. М. Застольные песни башкир // А. Харисов и актуальные проблемы филологии: Мат-лы Всерос. науч.-практ. конф. (с междунар. участием). Уфа: ИИЯЛ УНЦ РАН, 2014. C. $123-126$.

Хакимьянова 2019 - Хакимьянова А. М. Башкирские народные такмаки // Oriental Studies. 2019. № 3. С. 492-501.

Хакимьянова, Султангареева 2018 - Хакимьянова А. М., Султангареева Р. А. Башкирские свадебные песни: текст и практика. Уфа: Мир печати, 2018. 176 с.

126. (In Russ.)

Khakimyanova A. M., Sultangareeva R. A. Bashkir Wedding Songs: Text and Practice. Ufa: Mir Pechati, 2018. 176 p. (In Russ.)

Mergen K. A. Family and household rites. In: Mergen K. A. Literature. Folklore. Literary Heritage. Ufa, 1976. Pp. 31-76. (In Russ.)

Nadrshina F. A. (comp.) The Spiritual Treasures: Folklore of Asylykul, Dyoma, Urshak Bashkirs. Ufa: Republican Center of Folk Culture, 1992. 76 p. (In Bash.)

Salmanova L. K. Bashkir wedding: lamentations and rites of passage. Vatandash. 2007. No. 1. Pp. 128-129. (In Russ.)

Suleymanov A. M., Sultangareeva R. A. (comps.), Khusainov G. B. (ed.) Bashkir People's Creative Activity. Vol. 1: Rites Folklore. Ufa: Kitap, 1995. 560 p. (In Bash.)

Suleymanov A. M., Sultangareeva R. A. (comps.), Zaripov N. T., Yusupov R. M. (eds.) Bashkir People's Creative Activity. Vol. 12: Ritual Folklore. Ufa: Kitap, 2010. 592 p. (In Russ.)

Suleymanov R. S. Folklore of the Urals: The Pearls. Ufa: Kitap, 1995. 248 p. (In Russ.)

Sultangareeva R. A. (comp.) From Memories of the Nation - to the Nation: Earliest Works by Bashkir Folklorists. Ufa: Ufa State Academy of Arts, 2012. 134 p. (In Bash.)

Sultangareeva R. A. Human Life and Ritual: A Folklore and Ethnographic Study of Bashkir Family Rites. Ufa: Gilem, 2006. 344 p. (In Russ.) 